\title{
Valerio Magrelli, Nero sonetto solubile
}

\section{Ida Merello}

\section{(Q) OpenEdition}

\section{Journals}

\section{Edizione digitale}

URL: http://journals.openedition.org/studifrancesi/6987

DOI: 10.4000/studifrancesi.6987

ISSN: 2421-5856

\section{Editore}

Rosenberg \& Sellier

\section{Edizione cartacea}

Data di pubblicazione: 1 septembre 2010

Paginazione: 395-396

ISSN: 0039-2944

\section{Notizia bibliografica digitale}

Ida Merello, «Valerio Magrelli, Nero sonetto solubile», Studi Francesi [Online], 161 (LIV | II)| 2010, online dal 30 novembre 2015, consultato il 09 janvier 2021. URL: http://journals.openedition.org/ studifrancesi/6987 ; DOI: https://doi.org/10.4000/studifrancesi.6987

Questo documento è stato generato automaticamente il 9 janvier 2021.

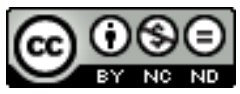

Studi Francesi è distribuita con Licenza Creative Commons Attribuzione - Non commerciale - Non opere derivate 4.0 Internazionale. 


\title{
Valerio Magrelli, Nero sonetto solubile
}

\author{
Ida Merello
}

\section{NOTIZIA}

VALERIO MAGRELLI, Nero sonetto solubile, Bari, Laterza 2010, pp. 230.

1 In Folie Baudelaire Calasso percepiva Baudelaire come un'onda dilagata fino a noi e responsabile della nostra visione del mondo. Magrelli si sofferma invece su di un unico sonetto, Recueillement, indagando la sua «inoculazione», ossia su tutte le sue possibili influenze, a livello di calco, antifrasi, parodia, nella letteratura francese del Novecento (con l'inclusione del francofilo Nabokov) come forma esemplare di trasmissione letteraria. Il titolo è modulato su Poisson soluble di Breton, e rappresenta perfettamente quel grado di solubilità del testo baudelairiano che l'A. intende rintracciare non solo nei suoi aspetti evidenti, ma anche nelle rimodulazioni più criptiche; mentre il nero sta a indicare la connotazione funerea, che tuttavia porta con sé il suo rimedio di consolazione: così come il pharmacon, dice l'A., rappresenta contemporaneamente il veleno e la sua cura. Frutto di vent'anni di ricerche e sorretto da un'infinita varietà di elementi critici, il volume raccoglie studi su Valéry, Michaux, Céline, Prévost, Colette, Nabokov, Beckett, Perec e Queneau. Le uniche opere critiche ammesse in questa carrellata appartengono a Valéry e Prévost. Valéry, in quanto un suo saggio del 1924, ripreso nel 1939, nonostante salvi del sonetto essenzialmente l'incipit e la fine, lo consacra come uno dei momenti più alti della poesia e così lo addita alle generazioni future come vertice espressivo; Prévost (1943) perché partecipa dell'attività creativa, dal momento che per mostrare la bellezza insostituibile degli alessandrini del testo li traspone in ottonari. Per quanto riguarda invece l'autentica «inoculazione» nelle opere letterarie, l'unico caso di accostamento congetturale da parte dell'A. è quello di Repos dans le malheur di Michaux (1930), in cui individua la struttura ossimorica baudelairiana pur con la sostituzione del Malheur alla Douleur. Per gli altri l'A si basa invece su elementi espliciti. In Voyage au bout de la nuit, Céline parte dall'allusione a un verso del sonetto per riproporlo poi in forma parodica; in Noces, Colette (1944) esibisce un processo di abbassamento del testo nel momento in cui gli invitati al matrimonio si 
divertono a degradarlo, ma poi tradisce quanto l'inoculazione sia più profonda in un riferimento non parodico successivo. Per quanto impalpabile sembri invece l'accenno a Recueillement in Lolita di Nabokov, la francofilia dello scrittore, nonché la sua continua frequentazione di Baudelaire, rende pienamente convincente l'ipotesi dell'A. di individuare in «Sois-sage ma douleur» l'ipotesto di «Fa' la brava Dolores», corroborata dall'osservazione di Proust circa l'atteggiamento di maternage del poeta nei confronti della sua pena. In Fin de partie di Beckett invece l'A. ricorda la lenta emersione dalla memoria da parte di Hamm di un verso del sonetto, prima che egli mimi la propria morte coprendosi il volto col fazzoletto: gesto analogo, secondo Magrelli, al sudario in cui la Notte incede negli ultimi due versi del testo di Baudelaire. Se in Queneau il punto di contatto è una quartina del componimento conclusivo di Fendre les flots (1969), più complesso è l'omaggio in negativo in La Disparition di Perec, dove per la contrainte della mancanza della $e$ la douleur diventa chagrin e loin d'eux è trasformato in loin d'ici. L'A. ipotizza che proprio questo eux abbia scatenato il desiderio di Perec di "lipogrammare" il testo, per esibire nella scomparsa di «eux» gli scomparsi nei campi di sterminio, in primis i suoi genitori.

2 Houellebecq esibisce invece in Particules élémentaires (1998) la lettura di un professore distratto, irriso dall'allievo che sembra cogliere contemporaneamente lo spirito del sonetto baudelairiano e la morte della poesia operata dalla sciattezza del professore.

3 L'A. vede l'inoculazione del sonetto procedere ben oltre i limiti letterari, per invadere tutta la nostra cultura, e ricorda come l'ultimo sms alla madre di Marie Trintignant prima di essere uccisa da Cantat fosse un esplicito riferimento a Recueillement. 